\title{
Is risk itself a climate-related harm?
}

\author{
Rosemary Lowry
}

Received: 7 April 2009 / Accepted: 1 July 2010 / Published online: 15 December 2010

(C) The Author(s) 2010. This article is published with open access at Springerlink.com

\section{Introduction}

The benefits and losses associated with different climate change scenarios have been widely discussed. The Stern (2006) warns that if we continue on a path of 'business as usual' there is a risk of consequences such as a permanent loss of more than $5 \%$ of global per-capita consumption, ${ }^{1}$ worldwide deaths from malnutrition and heat stress and the spreading of diseases such as malaria and dengue fever. It also claims that there is a risk that 200 million more people could become permanently displaced by the middle of the century, and $15-40 \%$ of species could face extinction. ${ }^{2}$ If these consequences materialise, they will obviously be the source of great harm. In this paper however I wish to draw attention to a less obvious, and thus largely neglected, source of climate-related harm. This is the harm that comes from risk itself, where I understand 'risk' as the probability of some adverse event which may or may not occur. That is, I wish to examine the harm that comes from the mere probability of adverse climate events (where strictly speaking, it may be the awareness of this probability, or an effect of this probability, which causes the harm). ${ }^{3}$ I will argue that risk in this sense decreases wellbeing, apart from the adverse consequences that are the subjects of that risk.

\footnotetext{
${ }^{1}$ The review also claims that there may be greater risks to the climate from dynamic feedbacks and from heightened climate sensitivity. If these are included, they estimate the total cost to be around $20 \%$ of current per-capita consumption, now and forever. See p. 164 for a summary of these conclusions.

${ }^{2}$ See p. 56 of the Stern Review: The Economics of Climate Change, http://www.hm-treasury.gov.uk/d/ Part_II_Introduction_group.pdf.

${ }^{3}$ Of course I do not mean that it is the number which causes the harm, but the features of the world represented by this number.
}

R. Lowry $(\bowtie)$

The Section of Philosophy \& Ethics, School of Innovation Science,

Eindhoven University of Technology, P.O. Box 513,

$5600 \mathrm{MB}$, Eindhoven, Netherlands

e-mail: R.J.Lowry@tue.nl 
It is important to draw attention to the harm that comes from risk itself (i.e. the harm that comes from the probability of some adverse event), because when decision-makers become aware of a risk to the environment or human, animal or plant health, the question of appropriate protective measures arises. In order to select the most appropriate course of action, decision-makers must obtain the most complete evaluation possible of the consequences of different courses of action. In order to obtain the most complete evaluation possible, we must compare all the foreseeable positive and negative consequences of the proposed actions or inaction. According to the European Commission, if we are to properly manage climate risks, an examination of these pros and cons cannot be reduced to an economic costbenefit analysis. ${ }^{4}$ The relevant consequences are wider in scope and include noneconomic considerations. Importantly, the Commission affirms that "requirements linked to the protection of public health should undoubtedly be given greater weight than economic considerations" (Communication from the Commission on the Precautionary Principle, p. 20). Given the Commission's stipulation that we should prioritize public health when managing climate risks, any harm to wellbeing that is caused by risk itself should be included in the analysis of the positive and negative consequences of the envisaged actions. At present however, this disvalue is a largely neglected source of climate-related harm.

In this paper I do not suggest an answer about what ought to be done all things considered with regard to climate risks. My argument is contained to establishing the claim that placing people at risk of adverse climate events thereby decreases their wellbeing. As the role that this harm will play in determining what ought to be done depends on the theory of ethics accepted, it is beyond the scope of this paper to take a stand on the issue. However, if my argument is accepted, this largely unacknowledged source of harm should be $a$ determinant of what we ought to do all things considered. ${ }^{5}$ Consequently, the claim that the mere probability of adverse climate events decreases our wellbeing has implications beyond those addressed in this paper.

In the next Section I outline the three main theories of wellbeing and discuss the challenges met by each theory. Section 3 will then demonstrate that the mere probability of adverse climate events decreases wellbeing, according to each of the three theories of wellbeing. I conclude that this harm should be included in evaluations of different courses of action responding to climate change.

\footnotetext{
${ }^{4}$ According to the European Commission, the proper management of risks also requires proportionality, non-discrimination, consistency and the examination of scientific developments. See Communication from the Commission on the Precautionary Principle Brussels, 02.02.2000 COM (2000) 1, at http://ec.europa.eu/dgs/health_consumer/library/pub/pub07_en.pdf.

${ }^{5}$ For instance, according to utilitarianism, an action ought to be performed if and only if the surplus of good consequences over bad ones is at least as great as that of all alternative actions. The harm created by risk itself will thus help to determine, along with other good and bad consequences, what ought to be done. According to other ethical theories however, it is necessary to also consider issues related to duties, justice or human rights before one can decide on a specific course of action. This is not to say that such theories deny the importance of calculating costs and benefits. The claim that risk itself creates harm may still matter to the conclusion about what we ought to do according to such theories. But this harm may have less influence on the conclusion about what ought to be done all things considered than in utilitarianism. Importantly however, justice may require that we do our best to ensure that future people have a certain level of wellbeing, and thus the claim argued for in this paper may be relevant in other ways to such ethical theories.
} 


\section{Wellbeing}

The study of wellbeing is a study of those things that make a life go better. It amounts to the notion of how well a person's life is going for that person (Crisp 2006). Following Scanlon (1998), Parfit (1984), Sumner (1996) and Griffin (1986), I will distinguish three main theories of wellbeing. I shall call them experiential theories, objective goods theories and desire-satisfaction theories.

Proponents of experiential accounts of wellbeing claim that one's wellbeing is constituted by the quality of one's experiences. Experiences are generally considered to be good (and thus contribute to one's wellbeing) if they are pleasurable, enjoyable or in some way desirable. ${ }^{6}$ This allows two agents whose external conditions are the same, but who have different experiences of these conditions, to differ in their levels of wellbeing. As an agent has privileged access to the quality of her own experiences, and as it seems likely that she will assess her own wellbeing in terms of how she experiences her life, experiential accounts of wellbeing are likely to give a measure of wellbeing that converges with an agent's own report of the standard of her wellbeing. If we take an agent to have some authority on the subject of her own wellbeing, as for instance Campbell seems to, in his claim that "people are able to describe the quality of their own lives... with a kind of direct validity that more objective measures do not have," (1981, p. 12) then the convergence of these assessments may be considered a virtue of experiential theories of wellbeing.

There is a substantial problem with an experiential account however, as it ignores what seems to be an important contributor to our wellbeing: the actual, rather than merely perceived, receipt of valuable things. Experiential accounts of wellbeing claim it is only those things that enter into one's experience which affect one's wellbeing. Consequently, where the experience of receiving some good and the experience where an agent falsely believes that he receives this good are indiscernible from the agent's perspective, they make an equal contribution to the agent's wellbeing. The failure to distinguish between these circumstances seems to be a failure to account for an important sense in which a life can go well (or badly). In Griffin's words:

If a father wants his children to be happy, what he wants, what is valuable to him, is a state of the world, not a state of his mind; merely to delude him into thinking that his children flourish, therefore, does not give him what he values.

(Griffin 1986, p. 13)

Such examples demonstrate an important fact that experiential accounts of wellbeing fails to capture: the actual and perceived receipt of valuable things is better for us than the merely perceived receipt of these things. That is, at the very least, it seems clear that if a child feigns love and respect in order to receive his father's monetary support, this is worse for the father than if his child genuinely cared about him.

Nozick (1974, ch. 3) also stresses the importance of factors other than our experiences in his discussion of an 'experience machine' that simulates valuable

\footnotetext{
${ }^{6}$ Jeremy Bentham is perhaps the most well-known supporter of a view of this kind. He claimed that the longer the duration of pleasure and the more intense the pleasure experienced, the better it is for the person who experiences it. J.S. Mill adopted a more sophisticated view of this kind.
} 
experiences. He argues that we should not plug into such a machine if we had the choice, as there are things that matter to us in addition to our experiences: doing certain things, being a certain way and being in contact with reality. Plugging into the experience machine would deprive us of such things and limit us to "a man-made reality" (Nozick 1974, p. 43). As there appears to be a significant divide between illusory and veridical experiences, this has led some theorists to focus instead on certain objective goods that they claim contribute to wellbeing.

An objective goods theory states that there are certain goods that are objectively good, and thus improve wellbeing in any life in which they are present. ${ }^{7}$ Similarly, any life in which these goods are absent will have diminished wellbeing. It is the actual rather than merely perceived presence of these goods in one's life that contributes to one's wellbeing. That is, an objective goods theorist would claim that it is the inherent worth of the objective goods, and not merely one's experience of them, which makes one's life go better. Examples of such goods might include health, enjoyment, accomplishment and autonomy. ${ }^{8}$

In order for the idea that there are objective goods to be plausible, such goods will have to be kept at the most general level. Given the diverse range of apparently good or worthwhile lives, a list of goods specific to one of these lives could not be shared by others with a vastly different lifestyle. Those goods that are essential components of an artist's wellbeing might not be components of an athlete's wellbeing. Moreover, while goods such as health, enjoyment, accomplishment and autonomy may be general enough to contribute to most people's wellbeing, there may still be some exceptions. Consider for instance the decidophobic ${ }^{9}$ who fears autonomy. It is at least arguable that having autonomy will not be valuable for such an agent. ${ }^{10}$ At the most then, we can claim that goods such as health, autonomy and enjoyment usually contribute to an agent's wellbeing.

Another objection to this theory is from those that claim that it is not independent facts about value which explain why such goods are valuable for us, but our desires for such goods. That is, some people believe that it is the fact that I want or prefer something which explains why it is good or bad for me. Consider Parfit's example,

After taking certain kinds of drug, people claim that the quality of their sensations has not altered, but they no longer dislike these sensations. We would regard such drugs as effective analgesics. This suggests that the badness of a pain consists in its being disliked, and that it is not disliked because it is bad. (Parfit 1984, p. 501)

Such examples may lead to the adoption of a desire-satisfaction account of wellbeing. According to such accounts, desire satisfaction occurs when certain desired states of affairs come true. If I desire that my grandchild goes to university, then my desire is satisfied (and my wellbeing increased) if and only if my grandchild goes to

\footnotetext{
${ }^{7}$ For an example of one kind of objective goods theory, influenced by Aristotle, see Hurka (1993).

${ }^{8}$ See James Griffin, Wellbeing, Chapter iii) and iv) for a discussion of objective goods.

${ }^{9}$ Walter Kauffman coined this term in his Without Guilt and Justice: From Decidophobia to Autonomy, (New York: Peter H. Wyden, Inc. 1973).

${ }^{10}$ For a defense of this view, see James Griffin, Wellbeing, Chapter 2, Sections 3 and 4.
} 
university. ${ }^{11}$ Desire-satisfaction theories of wellbeing thus deny there are prudential goods which are independent of an agent's awareness of, or desires for, the goods. ${ }^{12}$

One challenge for desire-satisfaction theorists is that there seem to be factors responsible for contributions to our wellbeing besides the mere satisfaction of our desires. We can see this in cases where an agent's desires reflect her disadvantaged circumstances. According to the present formulation of desire-satisfaction theories, such accounts fail to take the circumstances that have given rise to one's desires into consideration. Sen expresses this concern about desire-satisfaction theories on the basis of the desires that deprived or unfortunate people may have:

A person who has had a life of misfortune, with very little opportunities, and rather little hope, may be more easily reconciled to deprivations than others reared in more fortunate and affluent circumstances... since the hopelessly deprived lack the courage to desire much... their deprivations are muted and deadened in the scale of desire-fulfillment. (Sen 1987, p. 45-46)

It would consequently be a misguided (and morally repugnant) move to attach a high standard of wellbeing to the deprived and unfortunate on the basis that their meagre desires and aspirations are satisfied. While a satisfied slave may have a higher wellbeing than a dissatisfied slave, we should not equate a satisfied slave's wellbeing with a satisfied master's wellbeing. Other aspects of an agent's circumstances may influence the desires she forms and may affect her wellbeing in a way that is not reflected by a measure of her desire satisfaction.

A different problem facing desire-satisfaction theories of wellbeing is a practical one. It concerns the divergence between the enjoyment anticipated in an outcome or state of affairs and the actual enjoyment that the outcome or state of affairs brings. The actual enjoyment in satisfying our desires may be impossible to predict.

More sophisticated desire-satisfaction theories can avoid these difficulties by placing certain conditions on the desires whose satisfaction contributes to our wellbeing. Some theories specify an 'information' requirement. An information requirement implies that wellbeing is only increased when 'informed' desires are satisfied. A desire may be considered informed if an agent possesses all the information relevant to the object of the desire. By incorporating an information requirement, desiresatisfaction theories of wellbeing will avoid the implication that an agent's wellbeing is increased through the satisfaction of her desires, if such satisfaction involves states of affairs that were unanticipated and unwelcome. Such a requirement may also reduce the number of cases where the desire-satisfaction theory implies that an agent's wellbeing is increased when her desires have arisen out of her deprived and unfortunate circumstances. That is, information about the facts that can induce an agent to form her desires may encourage different desires, ones that are not reflective of one's deprived and unfortunate circumstances.

It is also common for desire satisfaction theorists to specify a 'rationality' requirement. A rationality requirement implies that wellbeing is increased only through the satisfaction of rational desires. A desire may be considered rational if the person

\footnotetext{
${ }^{11}$ James Griffin, Wellbeing, 14, and L.W. Sumner, Welfare, Happiness, and Ethics, 124, both give this type of definition of desire-satisfaction.

${ }^{12}$ Many economists see people's well-being as consisting in the satisfaction of preferences or desires.
} 
would desire its object, were he fully rational. What a person would desire were he fully rational is open to debate and will depend on the standard of rationality appealed to. This standard may be either minimal, requiring no more than consistency within one's overall set of preferences, or more stringent, requiring that one's desires be capable of surviving 'cognitive psychotherapy' (Sumner 1996).

\section{Risk and wellbeing}

Now that the three major theories of wellbeing have been discussed, I will argue that according to each of these theories, the mere risk of adverse climate events decreases wellbeing. As above, by the 'mere risk' of adverse climate events, I mean the mere probability of such events occurring, regardless of whether these events actually occur.

We have seen that according to experiential accounts of wellbeing, one's wellbeing is constituted by the quality of one's experiences. Some activities involving risks of adverse events provide pleasurable experiences for people, such as gambling or perhaps base jumping. The risks in such activities involve the excitement of winning, or the adrenaline rush of free-falling. However, the risks of adverse climate events are quite different. For instance, we saw that according to the Stern review, if we continue on a path of 'business as usual', there will be a risk of a permanent loss of more than $5 \%$ of global per-capita consumption, worldwide deaths from malnutrition and heat stress and the spreading of diseases. In addition, while there is no consensus on the probability of an abrupt change, scientists are concerned that disruption of the climate system may pass critical thresholds, resulting in abrupt rather than gradual changes and associated rapid impacts on health. ${ }^{13}$

The risks associated with climate change are not of the type which is counterbalanced by an adrenaline rush or the anticipation of winning, as with those risks involved in base jumping or gambling. Rather they are the type of risk which will bring great stress and worry to those who are aware of them. The harm caused by the risk of adverse events has been seen in cases where people have been exposed to asbestos. ${ }^{14}$ The very awareness of the potential consequences of exposure to asbestos has been reported to generate anxiety, fear, and panic for those who have been exposed to it. Because the mere awareness of risk is enough to cause anxiety and fear, high courts in the U.S. and Britain have awarded pain and suffering damages to workers suffering from fears of developing cancer and other conditions. ${ }^{15}$ With regard to the risks of adverse climate events, the European Commission has claimed that the public is becoming increasingly aware of the risks to which the population

\footnotetext{
${ }^{13}$ See McMichael et al. (2004, p. 1553), Chapter 20: Global climate change in Comparative Quantification of Health Risks: Global and Regional Burden of Disease Attributable to Selected Major Risk Factors Vol 1, Edited by Majid Ezzati, Alan D. Lopez. Anthony Rodgers And Christopher J.L. Murray, World Health Organization Geneva.

${ }^{14}$ Again, strictly speaking it is the awareness of the risk that causes the anxiety. The point is that being placed at risk of some bad event can create harm apart from the realisation of that bad event.

${ }^{15}$ This conclusion was reached, for instance, in the following case: Norfolk \& Western Railway Company v. Freeman Ayers et al., 538 US 135, 155 L Ed 2d 261, 123 S Ct 1210[No. 01-963], Argued November 6, 2002. Decided March 10, 2003. United States Supreme Court.
} 
and their environment are exposed. ${ }^{16}$ Not only are risks of adverse climate events now widely publicised in the media, precautionary action is also being taken. The government of Tuvalu, for instance, has already begun negotiating migration rights to New Zealand as a precaution against the risks of displacement (Barnett and Adger 2003). Media attention and precautionary action raises the awareness of the risks that one's own generation faces, and the risks that one's children and grandchildren face. It is thus not just for one's own fate that one might fear, but for one's children's, and one's grandchildren's. Furthermore, it seems likely that as media attention and precautionary action will only increase, future people will be even more aware of the risks they face. The experiential theory of wellbeing thus implies that our own wellbeing and those of future generations will be diminished as a result of this awareness.

There is an important difference between cases where people have been exposed to asbestos and cases where people are exposed to risks arising from climate change. Presumably if one develops the diseases from which exposure to asbestos has placed them at risk, any harm caused by the probability of their developing these diseases will be replaced by the harm caused by the disease. At this point, the harm caused by the risk of developing the diseases will cease. This is also true in the case of climate change in the sense that the realisation of one climate-related consequence will put an end to the harm created by the probability of that particular circumstance occurring. However, the subjects of the risks associated with climate change are often not mere isolated events. Many climate-related risks are probabilities of an increase in rates or trends of some undesirable phenomena. For instance, during the twentyfirst century it is very likely (greater than $90 \%$ chance) that there will be an increase in warm spells and heat waves over most land areas and it is likely (greater than $66 \%$ chance) that there will be an increase in Intense tropical cyclone activity. ${ }^{17}$ Given this, the occurrence of a single cyclone will not put an end to the anxiety caused by the probability of an increase in cyclone activity. On the contrary, the occurrence of an extreme weather event is likely to raise awareness of the increased probability of other future weather extremes and may thus serve to make people more attuned to, and anxious about, the heightened probability of other extreme weather events. In this way, the realisation of an adverse climate event may lead to an exacerbation of the psychological harm caused by the risk of adverse climate events. Future generations may thus (in addition to being increasingly harmed by the realisation of adverse climate events) become increasingly vulnerable to the harm caused by the awareness of the probabilities of these events.

In summary, it is a plausible empirical claim that current and future people's awareness of the risks to which they are exposed may induce experiences of anxiety and fear. It seems that unlike those cases where people have been exposed to asbestos, there is no good reason to think that this harm will cease when adverse

\footnotetext{
${ }^{16}$ Communication from the Commission on the precautionary principle (Commission of the European Communities, Brussels, 02.02.2000 COM (2000) 1, p. 8.

${ }^{17}$ IPCC (2007a): Summary for Policymakers. In: Climate Change 2007: The Physical Science Basis. Contribution of Working Group I to the Fourth Assessment Report of the Intergovernmental Panel on Climate Change [Solomon, S., D. Qin, M. Manning, Z. Chen, M. Marquis, K.B. Averyt, M.Tignor and H.L. Miller (eds.)]. Cambridge University Press, Cambridge, United Kingdom and New York, NY, USA.
} 
climate events begin to materialise. The experiential theory of wellbeing therefore implies that wellbeing will be diminished by the mere probability of adverse climate events.

As pointed out in the discussion of wellbeing above, there may be things that matter for our wellbeing beyond our immediate experiences. According to the objective goods theory, our wellbeing is increased by the presence of certain goods, where these goods might include health, enjoyment, accomplishment and autonomy. According to this account of wellbeing too, it seems that the mere risk of adverse climate events will decrease wellbeing. That is, regardless of whether consequences such as flood, drought and disease actually occur, the mere risk of such consequences will itself diminish the presence of objective prudential goods in people's lives. We can see this on two different counts. Firstly, I have claimed that if people are aware of the risks to which they have been exposed, these risks will diminish the quality of people's experiences by inducing fear and anxiety. With regard to the objective goods which contribute to a person's wellbeing, the experience of fear and anxiety will limit the amount of enjoyment and at least the quality of psychological health the person can have.

Even if people aren't aware of the risks however, the objective goods theory of wellbeing suggests that people's wellbeing is still reduced by being placed at risk. By exposing future people to risks without their consent, this reduces their autonomy, which is also often claimed to be an objective prudential good. Individual autonomy is generally understood as the capacity to be one's own person, to live one's life according to reasons and motives that are taken as one's own and not to be directed by considerations, desires, conditions and characteristics that are imposed externally (Christman 2008). It may not seem immediately plausible to claim that the risks associated with climate change reduces people's autonomy, as we might think that any adverse effects on someone's autonomy must come from the actual harm that is the subject of risk, not from the risk itself. So while we might say that exposing people to risks of adverse climate events involves the probability of affecting people's autonomy, we might think that provided people are unaware of that risk, it cannot by itself affect people's autonomy. ${ }^{18}$

In making the case that risk (in the sense of the probability of harm) decreases one's autonomy, we should note that in order to be autonomous, or in order for autonomy to have its proper value, one must have more than the capacity to live one's life in the way one chooses. A person must also have the freedom, or opportunity, to exercise this capacity. That is, if I am autonomous in the sense that my desires, values and plans are independent and authentic, but I am not free, or lack the opportunity, to satisfy my desires and carry out my plans, then such 'autonomy' will be of little value to me. This is relevant to the risks associated with climate change, because by exposing someone to these risks (to which they have not consented) we reduce the extent of opportunity and freedom that the person has to satisfy their desires and carry out their plans. Their extent of opportunity and freedom is reduced because their success at satisfying their desires and carrying out their plans becomes more unlikely.

An analogy may help to make the point. Suppose that my ambition and plan is to backpack through Europe. My friends, who think this is unsafe, but who know

${ }^{18}$ I thank an anonymous referee for pressing this point. 
that they will be unable to dissuade me from going, set out to prevent my leaving on the plane I have booked. Unbeknown to me, they take various actions which substantially reduce my chances of catching the plane and undertaking the trip I have planned. For instance, they offer almost irresistible bribes to the taxi-driver to persuade him to not pick me up, they steal my passport and they attempt to cause a bomb scare at the airport. Despite the fact that such efforts would normally succeed in thwarting my plans to catch the plane, their attempts are futile. The taxi driver is incorruptible, they steal my Australian passport but I also have a British passport, and they are prevented by security guards from entering the airport. It seems in this case that despite their failure, and despite my lack of awareness of their efforts, my friends manage to limit my autonomy by substantially reducing the chance of my achieving my ambition and carrying out my plan. My autonomy is reduced because despite my taking all reasonable actions in preparation for carrying out my plans, my friends' actions make it very unlikely that I will succeed. In this sense I am not really free to carry out my plan. It is instead a fluke that I still manage to carry out of my plan; my getting on the plane is a matter of luck (or my friends' bad luck). Another way of putting this point is to say that the outcome where I catch the plane is not 'robust', where a robust outcome is one that we can confidently expect to occur across a wide variety of situations similar to the actual situation (where my friends and I perform the same actions). Because the extent of opportunity and freedom I have to carry out my plan is substantially diminished, my autonomy is reduced, ${ }^{19}$ regardless of whether I am aware of this fact. Similarly, by exposing people to risks of adverse climate events, we reduce the extent of opportunity and freedom that they have to satisfy their desires and carry out their plans, regardless of whether they are aware of this fact, and regardless of whether the adverse climate events materialise. In this way, the mere probability of adverse climate events reduces autonomy.

In summary, by exposing people to risks of adverse climate events, such as disease and displacement, we limit their enjoyment and at least their quality of psychological health. Their autonomy is also diminished, even in the absence of their awareness of the risks. Consequently, according to objective goods theories of wellbeing, by exposing people to risks of adverse climate events, we thereby reduce their wellbeing.

The third theory of wellbeing discussed above claimed that our wellbeing is comprised of desire satisfaction. We saw that the most plausible versions of this theory attach information and rationality conditions to those desires that contribute to wellbeing. So what would rational and informed people desire with regard to the risks of adverse climate events?

What a fully rational and informed person would desire with regard to risks of adverse climate events depends in part on whether he cares about his own wellbeing. In order to ensure that a fully rational and informed person would desire to promote his own wellbeing, the view that rationality is substantive may have to be adopted, where substantive rationality requires people to care about certain things, rather than merely deliberate in certain ways. ${ }^{20} \mathrm{I}$ will not try to argue here that rationality is substantive, but instead claim that even on a very minimalist understanding of

\footnotetext{
${ }^{19}$ Or alternatively, my freedom to exercise my autonomy is substantially reduced, and thus the value of such 'autonomy' is much reduced.

${ }^{20}$ See Derek Parfit, 'Reason and Motivation', The Aristotelian Society, (supp. Vol. 71, 1997) for a discussion of substantive rationality.
} 
the notion of rationality, it seems that most rational people do happen to care about their own wellbeing. Without a definitive account of wellbeing, it is of course difficult to say what future, informed, rational people who care about their wellbeing would desire. I believe however that putting aside the specific explanation for why the occurrence of adverse climate events diminishes our wellbeing (i.e. whether it is through their connection with objective goods, our experiences or our desires), any plausible theory of wellbeing must acknowledge that consequences such as malnutrition, pollution, disease and displacement are factors that will lead to a decrease in wellbeing. Future people who care about their wellbeing will thus want to reduce the risks of such consequences.

In addition, it is plausible that informed, rational people think that their experiences, enjoyment, health and autonomy matter to their wellbeing. ${ }^{21}$ With full information, future people will know that the harm caused by the mere probability of adverse climate events diminishes the quality of their experiences and also their enjoyment, health and autonomy. They may thus desire to reduce the risks placed on them on a second ground: that risk itself diminishes their wellbeing. In summary, if future people care about their own wellbeing, it is likely that they will desire to reduce their exposure to the risks of adverse climate events. These desires will not be satisfied, and their wellbeing will thus be diminished (according to the desiresatisfaction theory), if they are exposed to risks of adverse climate events.

Of course, in addition to the negative impacts which will arise from a current failure to mitigate and reduce climate risks, there may be positive impacts. If we refrain from investing in mitigation strategies which lower the risks of adverse climate events, future people may inherit other benefits such as a better financial system, or an improved health system. We might thus question whether informed rational people (who care about their own wellbeing) would desire that we invest in actions which will lower climate risks. However, unless scientists turn out to be quite wrong about the seriousness of the expected consequences, it seems very likely that exposing future generations to higher risks of adverse climate events will on the whole be worse for them. It thus also seems likely that future informed rational people caring about their own wellbeing will desire to reduce the risks of adverse climate events.It is thus plausible to think the desires of future informed rational people will be frustrated if we expose them to greater climate risks. Thus, as with the experiential theory and the objective goods theory, we see that according to desire satisfaction theories of wellbeing, the mere probability of adverse climate events can diminish wellbeing, even if these events do not materialise.

\section{Conclusion}

The brief survey given above of the three main theories of wellbeing and the discussion of risk has revealed the following: each theory implies that the risks of adverse climate events will diminish the wellbeing of current and future generations,

\footnotetext{
${ }^{21}$ Note that I am not supposing that informed, rational people will hold a desire-satisfaction theory of wellbeing. I am only concerned with the desires and beliefs that future informed, rational people are likely to have. This will tell us, according to the desire-satisfaction theory, whether their desires are likely to be frustrated and thus their wellbeing diminished.
} 
regardless of whether these events materialise. In particular, we saw that as the risks associated with climate change do not involve the thrill of a gamble, but instead risks of adverse events such as disease or displacement, the awareness of these risks will induce unpleasant experiences. Therefore, the experiential theory of wellbeing implies that the risks of adverse climate events will diminish wellbeing. In addition, according to the objective goods theory of wellbeing, health, enjoyment, accomplishment and autonomy may be objective prudential goods. We saw that at least three of these four goods are likely to be diminished by placing people at risk. In contrast to these two theories, desire-satisfaction theories of wellbeing claim that when people are rational and informed, their desire-satisfaction makes its own contribution to wellbeing. It seems likely that rational, informed people will desire to minimise the climate risks placed on them. By putting future generations at higher risks of adverse consequences we thus impede their desire-satisfaction and therefore diminish their wellbeing, according to desire-satisfaction theories. According to each of the main theories of wellbeing then, exposing people to the risks associated with climate change will, in general, decrease their wellbeing, regardless of whether these events materialise.

As acknowledged earlier, the realisation of adverse climate events will obviously be the main source of climate-related harm. However, the harm that comes from the mere probability of adverse climate events may not be insignificant, and should thus be included when we compare the positive and negative consequences of proposed actions. In particular, the management of risk and a decision about the appropriate course of action should be based on the most complete evaluation possible of the foreseeable benefits and harms of different courses of action. The diminished wellbeing caused by the mere probability of adverse climate events should thus be included in this evaluation. This point gains importance when considered alongside the European Commission's stipulation that when weighing the pros and cons of different responses to climate risks, we should prioritise public health over economic considerations. If public health is to be prioritised in this way, then this provides further reason for thinking that in order to properly manage climate risks, we must account for the loss of wellbeing brought about by risk itself.

Open Access This article is distributed under the terms of the Creative Commons Attribution Noncommercial License which permits any noncommercial use, distribution, and reproduction in any medium, provided the original author(s) and source are credited.

\section{References}

Barnett J, Adger WN (2003) Climate dangers and atoll countries. Clim Change 61(3):321-337

Campbell A (1981) The sense of well-being in America: recent patterns and trends. McGraw-Hill, New York

Christman J (2008) Autonomy in moral and political philosophy. In: Zalta EN (ed) The Stanford encyclopedia of philosophy. Available via DIALOG. http://plato.stanford.edu/archives/ fall2008/entries/autonomy-moral/

Crisp R (2006) Well-Being. In: Zalta EN (ed) The stanford encyclopedia of philosophy. Available via DIALOG. http://plato.stanford.edu/archives/win2006/entries/well-being/

Griffin J (1986) Wellbeing: its meaning, measurement and importance. Clarendon, Oxford

Hurka T (1993) Perfectionism. Clarendon, Oxford

Nozick R (1974) Anarchy, state, and utopia. Basil Blackwell, Oxford

Parfit D (1984) Reasons and persons. Clarendon, Oxford 
Scanlon T (1998) What we owe to each other. Harvard University Press, Cambridge

Sen A (1987) On Ethics and Economics. Oxford, Basil Blackwell, $131 \mathrm{p}$

Stern N (2006) Stern Review on The Economics of Climate Change (pre-publication edition).

Executive Summary. HM Treasury, London. Archived from the original on 2010-01-31.

http://www.webcitation.org/5nCeyEYJr. Retrieved 2010-10-20

Sumner LW (1996) Welfare, happiness, and ethics. Clarendon, Oxford

\section{Reports}

Communication from the Commission on the precautionary principle (Commission of the European Communities, Brussels, 02.02.2000 COM) (2000) 1 at http://ec.europa.eu/dgs/health_consumer/ library/pub/pub07_en.pdf

IPCC (2007a) Summary for policymakers. In: Solomon S, Qin D, Manning M, Chen Z, Marquis M, Averyt KB, Tignor M, Miller HL (eds) Climate change 2007: the physical science basis. Contribution of working group I to the fourth assessment report of the intergovernmental panel on climate change. Cambridge University Press, Cambridge, United Kingdom and New York, NY, USA

McMichael AJ, Campbell-Lendrum D, Kovats S, Edwards S, Wilkinson P, Wilson T, Nicholls R, Hales S, Tanser F, Le Sueur D, Schlesinger M, Andronova N (2004) Chapter 20: global climate change in comparative quantification of health risks: global and regional burden of disease attributable to selected major risk factors. In: Ezzati M, Lopez AD, Rodgers A, Murray CJL (eds) World health organization Geneva, vol 1. http://www.who.int/publications/cra/chapters/volume2/ 1543-1650.pdf 